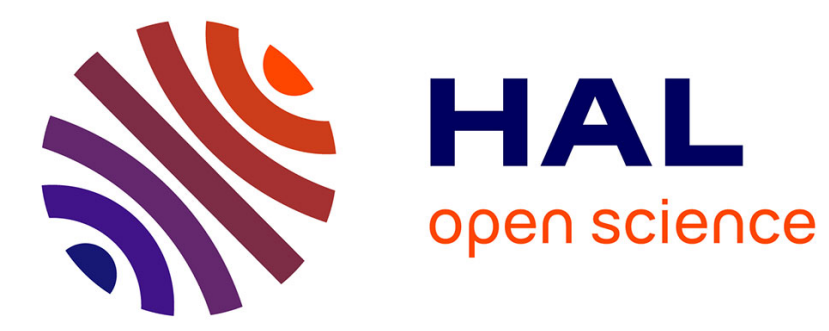

\title{
Quantifying uncertainty in LCA-modelling of waste management systems
}

Julie Clavreul, Dominique Guyonnet, Thomas H. Christensen

\section{To cite this version:}

Julie Clavreul, Dominique Guyonnet, Thomas H. Christensen. Quantifying uncertainty in LCA-modelling of waste management systems. Waste Management, 2012, 32, pp.2482-2495. 10.1016/j.wasman.2012.07.008 . hal-00763701

\section{HAL Id: hal-00763701 https: / hal-brgm.archives-ouvertes.fr/hal-00763701}

Submitted on 11 Dec 2012

HAL is a multi-disciplinary open access archive for the deposit and dissemination of scientific research documents, whether they are published or not. The documents may come from teaching and research institutions in France or abroad, or from public or private research centers.
L'archive ouverte pluridisciplinaire HAL, est destinée au dépôt et à la diffusion de documents scientifiques de niveau recherche, publiés ou non, émanant des établissements d'enseignement et de recherche français ou étrangers, des laboratoires publics ou privés. 
1 Waste Management 32 (2012), pp. 2482-2495 - DOI information: 10.1016/j.wasman.2012.07.008

2

3

4

5

Quantifying uncertainty in LCA-modelling of waste management systems

6

7 Julie Clavreul $^{*}{ }^{1}$, Dominique Guyonnet ${ }^{2}$ and Thomas H Christensen ${ }^{1}$

8

9

${ }^{1}$ Department of Environmental Engineering,

10 Technical University of Denmark, Kongens Lyngby, Denmark

11

${ }^{2}$ BRGM, ENAG BRGM-School, BP 6009, 3 Avenue C. Guillemin, 45060 Orléans Cedex, France

13

14

15

* Corresponding author

Department of Environmental Engineering

Building 115

Technical University of Denmark

19

DK-2800 Kongens Lyngby

Denmark

Phone: +4545251506

Fax: +4545932850

E-mail: julc@env.dtu.dk 
Abstract

28 Uncertainty analysis in LCA studies has been subject to major progress over the last years. In the context of waste

29 management, various methods have been implemented but a systematic method for uncertainty analysis of waste-

30 LCA studies is lacking. The objective of this paper is (1) to present the sources of uncertainty specifically inherent to

31 waste-LCA studies, (2) to select and apply several methods for uncertainty analysis and (3) to develop a general

32 framework for quantitative uncertainty assessment of LCA of waste management systems. The suggested method is a

33 sequence of four steps combining the selected methods: (Step 1) a sensitivity analysis evaluating the sensitivities of

34 the results with respect to the input uncertainties, (Step 2) an uncertainty propagation providing appropriate tools for

35 representing uncertainties and calculating the overall uncertainty of the model results, (Step 3) an uncertainty

36 contribution analysis quantifying the contribution of each parameter uncertainty to the final uncertainty and (Step 4)

37 as a new approach, a combined sensitivity analysis providing a visualization of the shift in the ranking of different

38 options due to variations of selected key parameters. This tiered approach optimizes the resources available to LCA

39 practitioners by only propagating the most influential uncertainties.

40

$41 \quad$ Keywords

42

43 LCA-modelling; waste management; uncertainty; sensitivity

44

45 


\section{Introduction}

Waste management has during the last decade been subject to a range of life cycle assessment (LCA; described in ISO, 2006) studies e.g. Damgaard et al. (2011), Finnveden et al. (2005), Lazarevic et al. (2010) and Pires et al. (2011). The purposes of these studies have been to help quantifying, for example, where in the waste management system the environmental loads and savings are taking place, which technologies are preferable under specific conditions, or the balance between material and energy recovery. LCA-models specifically focusing on waste management systems are available; see Gentil et al. (2010) for a review of the models.

As for any LCA study, results are subject to uncertainty due to the combined effects of data variability, erroneous measurements, wrong estimations, unrepresentative or missing data and modelling assumptions. Uncertainty is of two different natures: while epistemic uncertainty relates to an incomplete state of knowledge (Hoffman and Hammonds, 1994), stochastic uncertainty originates from the inherent variability of the natural world. Such uncertainty can be spatial (e.g. when the farming practice of land receiving compost varies spatially) or temporal (e.g. when the performance of a process varies with time). These two different natures of the uncertainty are usually treated together and referred to by the term "uncertainty".

Several authors have suggested typologies to describe the different types of uncertainties in LCAs. A well established one was introduced by Huijbregts (1998) and divides uncertainties into three groups (Lloyd \& Ries, 2007): (1) parameter uncertainties refer to the uncertainty in values due to e.g. inherent variability, measurement imprecision or paucity of data; (2) scenario uncertainties are due to the necessary choices made to build scenarios; and (3) model uncertainties are due to the mathematical models underlying LCA calculations. A first objective for this paper is to identify uncertainties in the particular context of waste-LCA studies.

Numerous methods have been developed to assess uncertainties and gathered under the term "uncertainty analysis". Their common goal is to assess the robustness of results, but they employ different mathematical techniques to reach this goal. Sensitivity analysis evaluates the influence of input changes on a model's results. The most common example is scenario analysis where assumptions are changed one-at-a-time. The procedure of calculating the uncertainty of a result due to all input uncertainties is referred to as "uncertainty propagation". In LCA, uncertainty assessments are increasingly included in the interpretation phase, and life cycle inventory (LCI) databases include increasing amounts of information concerning uncertainty (Finnveden et al., 2009). Lloyd and Ries (2007) reviewed quantitative uncertainty analysis in 24 LCA studies performed on various products and services. They found that stochastic modelling was the most frequently-used method to propagate uncertainties in LCA. This method propagates probability distributions using random sampling like the Monte Carlo analysis. However, they noted that many of the studies using such modelling seemed to select uncertainty distributions somewhat arbitrarily. 
Other methods have been proposed to more faithfully depict epistemic uncertainties in LCA modelling e.g. by Benetto et al. (2008) and Heijungs and Tan (2010) using possibility theory (Dubois and Prade, 1988), or Chevalier and Le Téno (1996) using intervals.

In LCA-modelling of waste management the amount of data available is still limited for establishing the inventories of the waste management systems under study (including data on waste composition, collection systems, source separation systems, recovery and conversion technologies, landfilling, and technologies for utilizing recovered materials). Few waste management LCAs have employed quantitative uncertainty assessment and these studies have often been limited to scenario analyses. Uncertainty propagation has been applied to specific waste management issues: for example Sonnemann et al. (2003) used stochastic modelling to evaluate emissions from an incinerator followed by a sensitivity analysis by means of correlation coefficients. Kaplan et al. (2009) used the same approach to evaluate and compare different waste management planning options, while Hung and Ma (2009) evaluated the relative contributions of the inventory, impact assessment, normalisation and weighting steps. Lo et al. (2004) applied a Bayesian Monte Carlo method to compare various waste treatment options. Each uncertainty analysis method has a specific goal and applicability depending on the nature of the model. Therefore the choice of the right tool may be difficult for LCA practitioners not familiar with uncertainty analysis.

Consequently we propose to select appropriate methods for waste-LCA models and show their benefits, complementarities and levels of complexity. The purpose of this paper is (1) to review the uncertainties commonly encountered in waste LCA-modelling, (2) to select and apply a range of methods for uncertainty analysis to waste LCA-modelling, (3) to develop a framework for the uncertainty analysis of waste management systems that combines various methods. The methods in this paper are applied to a case study that compares anaerobic digestion and incineration of organic kitchen waste in Denmark.

\section{Uncertainties in LCA of waste management systems}

This first section presents and discusses the sources of uncertainty typically encountered in LCA-modelling of waste management systems, based on the literature and experience acquired over the last decade. The characteristics and importance of an uncertainty analysis depend on the scope of the study and on the quality of the data available. The presentation and discussion below may provide valuable input for identifying sources of uncertainty in waste-LCAs, but each study should be associated with a specific identification. These uncertainties are presented in Table 1 using the framework introduced by Huijbregts (1998) that divides them into model, scenario and parameter uncertainties. Other frameworks have been developed that provide different insights into uncertainties in LCA such as by Reap et al. (2008) and Williams et al. (2009). Concerning the choice between attributional and consequential approaches or 
the choice of the impact categories included in the assessment, we realise they are issues but they were considered

111 methodological choices rather than uncertainties.

\subsection{Model uncertainties}

114 Model uncertainties arise from the mathematical equations used to model reality. Generic problems in LCA are

115 presented first, followed by model uncertainties more specifically found in waste management (See Table 1 for an overview of processes).

Intrinsic limitations of LCA: In most of the current models, emissions are aggregated over time and space before impact assessment is performed. This loss of spatial information generates uncertainty regarding the potential damage to the environment. Therefore several site-dependent impact assessment models are being developed, e.g. by Finnveden and Nilsson (2005) and Mutel and Hellweg (2009), but they are not yet implemented in commonly used methods. Furthermore, most of the LCA models assume linear processes, both for inventory and impact assessment, which may not reflect reality. For example, the effect of an emission on the environment and human health is modelled as linear while it often depends on the concentration in the environment and the period of exposure rather than on the total amount released over years (Ekvall et al., 2007). These simplifications are recognized by LCApractitioners and sometimes incorporated in the discussion section.

Impact assessment method: Life-cycle impact assessment (LCIA) methods hold large uncertainties because they attempt to model the impacts of each substance on humans and the environment by quantifying substance fate, pathways through the environment and potential effects. Several studies have illustrated the large discrepancies in results obtained with different LCIA methods e.g. Pizzol et al. (2011a, 2011b).

Models of waste treatment facilities in general: There are different approaches to model emissions from a waste treatment, as presented by Gentil et al. (2010). Emissions are usually modelled as process-specific (e.g. the emission of nitrous oxides from combustion does not depend on waste composition and thus can be modelled as a function of the quantity of entering waste) or waste-specific (e.g. the emission of mercury from an incinerator is a function of the quantity of entering mercury).

Model for waste collection: Driving, idling and compaction during collection of waste can be modelled in different ways: some models are very detailed and take into account the number of stops and the truck capacities, while others 
have generic emissions per tonne and/or per kilometre related to the diesel consumption for serving a certain urban area.

Model for biodegradation: Models for degradation in biological treatments take different approaches: some assume generic emissions and quantities of biogas and products while others calculate them based on waste composition and technical parameters as described for example by Boldrin et al. (2011). The same applies to landfill gas generation: it can be based for example on a first-order decay of degradable organic carbon as suggested by IPCC (2006), with varying numbers of waste fractions and properties. In addition, some models include site-specific gas collection, utilization and oxidation rates, while others assume default values. These modelling choices influence significantly the way emissions are quantified and consequently the environmental profile of the biological treatment or the

151 landfill.

Model for leaching: Leaching models are needed when applying materials on soil: in landfills (e.g. Damgaard et al., 2011), when using residues from thermal treatment (e.g. Toller et al., 2009) or residues from biological treatment (e.g. Boldrin et al., 2010). They estimate the amounts of pollutants transferred to soil and groundwater, or generic emissions per tonne of waste. They are usually based on experimental leaching tests but the behaviour of each pollutant depends highly on the geochemistry of the solid which is much more complex, with variations as a function of $\mathrm{pH}$, Eh, mineral phase solubility, etc. Therefore simplification of these processes generates model uncertainty.

Model for use of waste on land: Several models have been developed to quantify direct and avoided impacts of application of treated organic waste on agricultural land. Even if they have the same general approach, they use slightly different assumptions and calculation methods, e.g. with respect to plant uptake and the substitution of fertilizer production. Furthermore, agricultural practice and climate conditions affect nutrient cycling. This leads to variations in the results obtained when the same scenario is simulated in different models as shown in the comparison presented by Hansen et al. (2006).

\subsection{Scenario uncertainties}

Scenario uncertainties arise from the construction of scenarios when choices have to be made to model the different options under study.

System boundaries: The decision as to which processes to include in the assessment and which not to include is a 
should be included and the decision of leaving out processes, called a cut-off, should be justified. The most-frequent way of aggregating inventories is the process-LCA technique: a bottom-up approach which uses process-specific data gathered at the plant's scale and chains of processes (the top-down approach, called input-output-LCA, IO-LCA, is explained further). In process-LCA the practical difficulty is to evaluate a priori if a process will be significant and should be included in the assessment (Finnveden et al., 2009). This decision should be based on a scientific justification of the small environmental relevance of an input or output stream in comparison with the environmental relevance of the main streams: however this is often poorly justified (Suh et al., 2004). In waste management, the treatment of ashes or gypsum produced in incineration plants is often disregarded, but when making this choice, modellers must be certain of the absence of high-value metals in these ashes. Another common cut-off is the exclusion of capital goods from inventories. Frischknecht et al. (2007) have investigated the contribution of capital goods to several environmental impacts for a range of products and services of the database ecoinvent v1.2. In their study, capital goods contributed $6.6 \%$ of the acidification potential for incineration and $45 \%$ for sanitary landfills. The underestimation of impacts induced by cut-offs is often called a truncation error and several studies have tried to quantify it by using IO-LCA (Lenzen and Treloar, 2003). The IO-LCA originates from the input-output analysis and is a top-down technique: it uses sectorial monetary transactions to model exchanges between industries in a national economy (Suh et al., 2004). Thus where process-LCA has finite boundaries, IO-LCA includes all interconnections between industries. This means that capital goods are systematically included in IO-LCA, e.g. the impacts of the construction of an incineration plant, but also higher orders of service like the impacts of the transport sector for bringing materials to the construction site. In this way, IO-LCA gives a more complete impact assessment than process-LCA. However it suffers from other uncertainties in particular the high level of aggregation of data and the conversion between monetary and physical flows (Reap et al., 2008). A hybrid LCA technique has been introduced to take advantages of process-LCA and IO-LCA, see Suh et al. (2004) and Finnveden et al. (2009) for further details.

Another system boundary issue in consequential LCA is to consider all consequences of a decision. In the example of paper recycling, waste management systems can be expanded to take into account the effects of saved biomass: the newly available quantities of wood produced by forestry can be sent to energy production which will substitute for energy production from fossil fuels. Merrild et al. (2008) have shown that this change in system boundaries had a determining effect on assessing the environmental performances of paper recycling over incineration.

Representativity of technologies: Technology data are usually available only for a specific process or plant. This may limit the value of the data with respect to geographical and temporal representativity (e.g. ten year-old data from 
a single composting plant may not represent the composting plants operating in a large region for the next 20 years).

Furthermore, recovered materials may be traded on a market, maybe a world market, and since the plant receiving the recovered materials cannot be known, a world average technology should be used. However, such data are usually not available. For example, with respect to paper recycling, Merrild et al. (2008) compared global warming impacts when combining low- and high-performing recycling plants to low- and high-performing incineration technologies with energy recovery. This led to a large range of results, favouring in some cases recycling and in others incineration.

Moreover, LCA generally tries to assess future situations, typically for periods of 20 to 30 years in the case of waste management systems, while LCIs are normally based on former measurements. Spatial representativity is also questionable, especially when the study intends to evaluate a technology for an entire region or country. This applies to waste technologies but also to every process of material and energy productions included in available databases. They all have spatial, temporal and technological variabilities. Williams et al. (2009) suggested ways to improve the analysis of them by using IO-LCA, while Bovea et al. (2010) performed a sensitivity analysis where two different databases were tested: the ecoinvent database and the integrated waste management (IWM) model. the technology affected by the change. This marginal technology is most often difficult to select and depends largely on the extent of the change. Testing different alternatives is usually recommended, as done for example by Gentil et al. (2009) who implemented two different marginal electricity productions in their waste management systems.

Waste composition: Waste composition data are expensive to produce and only few data sets are available. As for technology data, this limits the geographical and temporal representativity of the data available and adds significant uncertainty if waste composition data are used outside their geographical and temporal window.

Time horizon of inventories: In LCA, all inputs should be traced back to raw materials and all outputs should be However in systems implying a time perspective like landfilling, forestry and agriculture, the definition of these boundaries is more complex (Finnveden et al., 2009). In these processes, emissions occur over long periods of time, e.g. carbon emissions to air from landfill or nitrogen leaching from application of compost on land. The choice of this time horizon will directly affect the inventories of these processes. In particular, landfill emissions of pollutants to water, air and soil occur over hundreds of years (Manfredi and Christensen, 2009). On the one hand, if a time horizon of 100 years is chosen, the toxic impacts from landfilling will appear very low. On the other hand, the impacts from emissions of pollutants leaching over hundreds of years 
cannot be put at the same level as the impacts from emissions occurring during the first 100 years. As a temporary solution, Hauschild et al. (2008) suggests to sum these impacts in separate toxicity categories and let the LCA practitioner discuss this issue in the weighting and interpretation phases.

The inclusion of carbon sequestration is directly related to the selection of a time boundary. When waste is landfilled or applied on land, a fraction of its biogenic carbon will not be degraded and emitted to the atmosphere. Depending on the study, this carbon sequestration is either accounted as an avoided emission of $\mathrm{CO}_{2}$ or else not considered (Christensen et al., 2009).

Time horizon of impact characterisation: This is the time period during which the fate, exposure and effects of each emission are modelled to calculate characterisation factors. A hundred years is a common choice but if other time horizons were selected, characterisation factors of emissions could vary significantly. For example the characterisation factors of methane for global warming rises from $7.6\left(\mathrm{~kg} \mathrm{CO}_{2}\right.$-eq / $\mathrm{kg} \mathrm{CH}$ ) for 500 years, to 25 for 100 years and up to 72 for 20 years (Ramaswamy et al., 2001). This has a particularly large influence on results from waste-LCAs because of the methane emissions from anaerobic decomposition of organic materials common in waste management systems.

Allocation: Allocation is one of the two ways of handling multi-functional processes (Finnveden et al., 2009). Waste management is often dealing with multi-functional processes such as an incineration plant which has the functions of treating waste, producing energy and recovering materials. In most cases, waste-LCAs will use systems expansion to deal with these processes by accounting for the substitution of primary energy and virgin material productions. However, system expansion is a demanding work and it is common to perform allocation for higher-layer processes for example in a combined heat and power plant. and weighting methods to use and their reference periods and scales. This will have a substantial influence on the importance given to each impact category and consequently on the final recommendation.

Each specific parameter in the model has inherent uncertainty and/or variability. The ones particularly relevant in the context of waste management systems are listed in Table 1; some of them will be further discussed in the case study. 


\section{Methods for uncertainty analysis of waste-LCA studies}

\subsection{Selection of methods}

Various methods for sensitivity and uncertainty analyses have been developed in scientific and engineering modelling; as presented by Saltelli et al. (2006). No single best method can be applied to all models: the choice depends on different criteria, namely the nature of the model, the requirements of the analysis and the resources available especially in terms of software (Morgan and Henrion, 1990). In this study, methods were selected that are adapted to different levels of available resource and to different waste-LCA models, that are relatively simple in terms of continuity and complexity.

It is fundamental to start by defining the requirements of the analysis in terms of expectations. A common pitfall is to perform an analysis without having a clear goal. Morgan and Henrion (1990) identified three key questions, which we address in the following sections:

- Sensitivity analysis: computing the effect of changes in input on model results,

- Uncertainty propagation: calculating the uncertainty of the model result due to all input uncertainties,

- Uncertainty contribution analysis: investigating where the output uncertainty originates.

\subsection{Sensitivity analysis}

Sensitivity analysis aims at identifying sensitive inputs. Local one-at-a-time approaches were selected because calculations are simple to implement and results easy to communicate, which is why these techniques have been the most used among the scientific community for years (Saltelli et al., 2006). Like any method, they have limitations in particular related to non-linearity in waste-LCA models but they provide useful first approximations. Other methods including global sensitivity analysis are presented by Saltelli et al. (2006) and might be more adapted to other types of models.

\subsubsection{Contribution analysis}

Contribution analysis is used very often, although not always identified as a sensitivity analysis. It is a self-evident method presented by Heijungs and Kleijn (2001). Contribution analysis consists in decomposing the LCA result (characterised, normalised or weighted impact) of a system into its individual process contributions, providing a quick overview of the important contributors. Processes that have both positive and negative impacts have to be subdivided into their sub-components, to avoid neglecting important processes. For example an incineration process might have an impact close to zero, but as the net total of high direct impacts (fossil $\mathrm{CO}_{2}$ emission from burning of 
plastic) and high avoided ones (produced electricity substituting fossil $\mathrm{CO}_{2}$ emissions from a coal-burning power plant).

\subsubsection{Perturbation analysis}

Perturbation analysis is used to assess the influence of parameter uncertainties (Heijungs and Kleijn, 2001). The aim is to determine the effect of an arbitrary change of single parameter values on the model's result. Each parameter value is individually varied by a small increment. The variation of the result is calculated and two ratios are particularly interesting to generate:

- The sensitivity coefficient (SC), which is the ratio between the two absolute changes.

$$
S C=\frac{\Delta \text { result }}{\Delta \text { parameter }}
$$

- The sensitivity ratio (SR), which is the ratio between the two relative changes. If a parameter has a SR of 2 , it implies that when increasing its value by $10 \%$, the final result is increased by $20 \%$.

$$
S R=\frac{\frac{\Delta \text { result }}{\text { initial_result }}}{\frac{\Delta \text { parameter }}{\text { initial__parameter }}}
$$

\subsubsection{Scenario analysis}

This sensitivity analysis consists in testing different options individually and observing the effect of these changes on the final result. The new results obtained for each scenario can easily be compared with the baseline results to identify the uncertainties that change some scenario result significantly or the ranking between alternatives.

\subsubsection{Combined sensitivity analysis}

In this analysis two parameters are varied simultaneously and the change in the results is observed, for example the difference between the two scenarios' results. The aim is to find the conditions for which the ranking of scenarios may change. This can be visualized in a two dimensional contour graph with contour lines showing the difference between the two scenarios. Scenario and model uncertainties could be analysed as well by performing separate calculations using different scenarios and models. 


\subsection{Uncertainty propagation}

Uncertainty propagation consists in propagating input uncertainties to calculate the result's uncertainty. Before propagating them, the practitioner has to choose a representation for these input uncertainties. A short introduction to the question of uncertainty representation is given in section 3.3.1. For this case study, the probability theory was adopted and a sampling propagation method selected. An analytical method could as well have been implemented, e.g. the first order approximation from the Taylor series as explained by Morgan and Henrion (1990), but it is impractical in the case of waste-LCA models because it requires lots of resources to express each LCA impact as a function of all input parameters. Hong et al. (2010) performed analytical uncertainty propagation in an LCA study. Among sampling methods, the Monte Carlo analysis was chosen because it is the most common method and the calculation was fast enough. If larger data or more complex modelling was used, a more efficient sampling method could be used such as the Latin Hypercube technique (Morgan and Henrion, 1990).

\subsubsection{Choice of representation}

Two main approaches can be chosen to represent uncertainties: the probability and possibility theories. In the case study presented below, it is assumed that all uncertainties can be represented by single probability distributions, even though there may be little data to substantiate these distributions in a statistical sense. If so-called "subjective" probability distributions (Savage, 1954) are selected for representing each uncertain parameter, then uncertainty propagation can be performed using the Monte Carlo method.

It is recognized, however, that this is not necessarily the case, especially considering that in real-world waste LCAs, epistemic uncertainties (reflecting paucity of information) generally dominate and therefore the modeller must rely on information sources such as expert (or personal) judgement, literature data, scarce measurements, etc. Alternative tools have been developed for representing uncertainty with an aim of consistency with available information. Such tools range from simple min-max intervals (as in Chevalier and Le Téno, 1996) to fuzzy sets (Dubois and Prade, 1988) or, more generally, imprecise probabilities (Shafer, 1976; Walley, 1991). Benetto et al. (2006) introduced the question of uncertainty representation in the field of LCA. As shown by many researchers (e.g. Ferson and Ginzburg, 1996), the arbitrary selection of probability distributions in the presence of incomplete information, especially associated with the common hypothesis of parameter independence, leads to severe underestimation of the likelihood of outlier results. Yet in a context of aversion to risk (e.g. of greenhouse gas emissions), outliers are of significant importance for the decision-making process. 


\subsubsection{Uncertainty propagation for all scenarios}

Monte Carlo analysis consists in randomly sampling the probability distribution of each uncertain parameter and then computing the result using the model. By performing this procedure a large number of times, a frequency histogram is constructed from the results and a probability distribution representing model results can be computed. While independence between model parameters is assumed below, dependencies between parameters can be accommodated using rank correlation methods (Connover and Iman, 1982). Adopting the point of view of Morgan and Henrion (1990), scenario and model uncertainties were not modelled in the probabilistic modelling: decision variables and value parameters are better assessed by performing separate uncertainty propagations using several «plausible » scenarios and models in the calculations, to reflect the variability of possible outcomes.

\subsubsection{Discernibility analysis}

While uncertainty propagation yields the probability distribution of the LCA results for each scenario, discernibility analysis provides the distribution of the difference between the scenarios' results (Heijungs and Kleijn, 2001). This can be important because some uncertainties may have the same influence on the scenarios but no influence on the differences between them. For instance, if two scenarios have the same consumption of electricity and the electricity mix is uncertain, both scenario results will have uncertainty but this should not affect the difference between them. Therefore the final decision should not be affected by this uncertainty.

\subsection{Uncertainty contribution analysis}

The uncertainty contribution analysis, also called key-issue analysis, consists in calculating the contribution of each parameter uncertainty to the calculated uncertainty (Heijungs et al., 2005). This method is different from perturbation analysis (Section 3.3.1) because input uncertainties are included in the calculation. An analytical calculation based on the first order approximation of the Taylor series was chosen because a simplified method (called later the SC method) was identified and applied. Other methods based on sampling uncertainty propagation can also be used, as described by Morgan and Henrion (1990). This method is based on the additive property of variances and uses the first-order terms of a Taylor Series expansion. Considering two variables $x$ and $y$ independent and normally (or at least symmetrically) distributed and $z$ a function of these variables, the variance of $z$ can be approximated by:

$$
\operatorname{var}(z) \approx\left(\frac{\partial f}{\partial x}\right)^{2} * \operatorname{var}(x)+\left(\frac{\partial f}{\partial y}\right)^{2} * \operatorname{var}(y)
$$




$$
\frac{\left(\frac{\partial f}{\partial x}\right)^{2} * \operatorname{var}(x)}{\operatorname{var}(z)}
$$

This contribution can be calculated analytically by defining the LCA result as a function of all parameters or by

391 approximating $\frac{\partial f}{\partial x}$ by $\frac{\Delta f}{\Delta x}$ considering that the variations of $x$ are relatively small. In this case the SC calculated using Equation 1 can be used:

$$
\frac{\left(\frac{\partial f}{\partial x}\right)^{2} * \operatorname{var}(x)}{\operatorname{var}(z)}=\frac{\left(\frac{\Delta f}{\Delta x}\right)^{2} * \operatorname{var}(x)}{\operatorname{var}(z)}=\frac{S C^{2} * \operatorname{var}(x)}{\operatorname{var}(z)}
$$

The results obtained with the analytical method and the SC method are compared in Section 4.4, to validate the SC method.

\section{Uncertainty modelling of a case study}

A hypothetical case study was set up in order to implement the methods, illustrate their features, identify their complementarities and propose a procedure for uncertainty quantification in waste LCA-modelling. While the focus was not on intense data collection, processes were taken from the EASEWASTE database (Kirkeby et al., 2006). For the purpose of clarity, the study only presents results for the impact category global warming. Hence normalisation and weighting are excluded, although these may be important steps contributing to uncertainty in LCA modelling. The latest characterisation factors from the IPCC (Forster et al., 2007) were used, on a 100-year time horizon. The two systems were modelled in the waste-LCA tool EASEWASTE (Kirkeby et al., 2006) and global warming factors (GWF) of all sub-processes were calculated. GWF are defined as the impact on global warming of the waste management system and expressed in $\mathrm{kg} \mathrm{CO}_{2}$-eq per tonne of waste treated. They were directly used for one-at-a-time sensitivity analyses, while they served as inputs in a MATLAB (R2010b version) program to perform the uncertainty propagation and the combined sensitivity analysis.

\subsection{Case study}

The case study aims at evaluating the benefits of sorting organic kitchen waste at the source and sending it to anaerobic digestion (AD), versus incineration together with residual waste. The functional unit is the collection and treatment of 1 tonne of organic kitchen waste from households in Denmark in 2011. 
The waste composition used originates from a sorting analysis of residual household waste in Denmark in

2001 by Petersen and Domela (2003). Organic waste was source-sorted from this waste with an assumed efficiency of $60 \%$ and, as erroneously-sorted materials, $5 \%$ of other combustible and non-combustible fractions. This corresponds to a composition of the sorted waste of $62 \%$ of vegetable food waste, $19 \%$ of animal food waste and $18 \%$ of ten other waste fractions. The detailed distribution as well as chemical composition and physical characteristics of each material fraction are presented in Table A.1 of supplementary information (Riber and Christensen, 2006a, 2006b).

In the first scenario, the organic waste is routed with the residual waste to an incineration plant, while in the second scenario the organic waste is sorted at the source and brought to an AD plant. Both plants are located 10 kilometres from the collection area and the vehicles transporting the waste use diesel and subscribe to the Euro3 exhaust standard. Two different collection technologies were used: organic waste collected as part of the residual waste used 3.27 L diesel/t, while separately collected organic waste used $7.2 \mathrm{~L}$ diesel/t.

The incineration plant used to represent incineration in Denmark is based on data from the plant located in Aarhus. It is a grate incinerator with mixed flue gas cleaning (two lines with wet, one with semidry) and has $20.7 \%$ electricity and $74 \%$ heat recovery based on the lower heating value (LHV) of the waste. Bottom ashes are transported 50 kilometres away to be landfilled, while air pollution control residues and fly ashes are shipped to Norway to be utilized for neutralization of waste acid.

The AD plant represents the state of the art in Western Europe (Møller et al., 2010). The gas produced is used in a gas turbine which recovers electricity (39\% efficiency) and heat (46\%). The digestate, which has $97 \%$ water content, is transported $30 \mathrm{~km}$ away to be used on agricultural land where it substitutes for the uses of $\mathrm{N}, \mathrm{P}$ and K fertilizers (Bruun et al., 2006). Carbon sequestration was accounted for. In both scenarios, the energy system is based on marginal electricity and heat productions from hard coal. Concerning the heat production, the substituted technology is a combined heat and power (CHP) plant located in Aarhus and the allocation is made based on exergy (See Cherubini et al., 2011 for a review of allocations methods).

\subsection{Results of sensitivity analysis}

\subsubsection{Contribution analysis}

Both scenarios have beneficial GWF: $-357 \mathrm{~kg} \mathrm{CO}$-eq/t waste collected for the incineration scenario and $-301 \mathrm{~kg}$ $\mathrm{CO}_{2}$-eq/t for the AD scenario. Figure 1 presents the contributions of all processes to the two scenarios' GWF and the details for the three processes that contribute both to direct and avoided emissions.

The two scenarios obtain almost equal benefits. The AD scenario obtains benefits from both the energy recovery (-398 $\mathrm{kg} \mathrm{CO}_{2}$-eq/t waste) and from the land application of digestate because of the substitution of fertilizer 
production (-60 $\mathrm{kg} \mathrm{CO}_{2}$-eq/t waste) and carbon sequestration (-41 $\mathrm{kg} \mathrm{CO}_{2}$-eq/t waste). Incineration obtains $21 \%$ more benefits from energy recovery than $\mathrm{AD}$ because the LHV of the collected waste is $4.8 \mathrm{GJ} / \mathrm{t}$ while the energy contained in the biogas produced anaerobically is $2.9 \mathrm{GJ} / \mathrm{t}$ waste. In addition, the heat recovery is much higher in the incinerator (74\%) than in the gas engine (46\%). At the same time, the AD scenario has larger loads than the incineration scenario. While the direct loads from the waste treatments are almost equal, the difference between the two scenarios' loads originates from the use on land of the digestate, which generates emissions of nitrous oxides and a consumption of diesel.

\subsubsection{Perturbation analysis}

Sensitivity coefficients (SC) and sensitivity ratios (SR) were calculated for all parameters of the two systems. Variations of $+10 \%$ and $-10 \%$ were generated for 55 parameters and only the highest of the two SR values was retained. Figure 2 presents, for each of the two scenarios, SR higher than 0.1 as absolute values. SC results are not presented; they will be used in the uncertainty contribution analysis.

This analysis highlights the parameters that have a large influence on each scenario's GWF. For example, the electricity recovery of the incinerator has a SR of 0.81 on the GWF of the incineration scenario. This means that, when increasing this parameter by $10 \%$, the benefits of the incineration scenario in terms of GWF increase by $8.1 \%$. Yet this is only a relative result: it does not show anything about how uncertain the result is, because it does not take into account the actual uncertainty of the input values.

The analysis shows that three parameters have SR values greater than 1 (as absolute value) for the incineration scenario, meaning that a variation of their value induces a larger relative variation in the scenario's GWF. These parameters are all related to the waste composition. For the AD scenario four parameters have such high SR: the methane yield and the electricity recovery are parameters of the digester, while the methane potential and water content are properties of the treated waste. It can be noted that the water content has a significant negative influence on both scenario performances as it dictates how much solid is available for energy production, since the amount of waste is depicted as wet weight.

The use of SR is particularly useful for evaluating the sensitivity of the model to parameter uncertainties and comparing them in order to select important parameters for the uncertainty propagation. It also helps to identify needs for further data collection. Between the two ratios, SC is quite easy to communicate but is not well suited for comparing the relative influence of parameters. SR enables comparison of the sensitivities of the model to different parameters. 


\subsubsection{Scenario analysis}

The impacts of several scenario and model uncertainties on both scenarios' GWF were investigated individually by the use of scenario analyses. The results are presented in Figure 3.

LCIA method: The use of the IPCC global warming potentials (GWP) from 2001 (Ramaswamy et al., 2001) did not have a significant impact on the two GWF (less than $1 \%$ variation).

Time horizon of impacts: The IPCC reports provide global warming potentials for three time horizons: 20,100 and 500 years. The results were tested for the two other time horizons and this choice changed the results significantly. Indeed, as the time horizon increases, the GWP of methane decreases. Consequently emissions of fossil $\mathrm{CO}_{2}$ become more and more important compared to the other emissions. When changing the time horizon from 100 to 20 years, the GWF of the incineration scenario became $27 \%$ more beneficial, while the one of the AD scenario increased by only $9 \%$. This is due to direct emissions of methane from the AD plant. With a time horizon of 500 years, the incineration scenario became $10 \%$ less beneficial, while the AD scenario became $1 \%$ more beneficial.

Carbon sequestration: The choice of not including carbon sequestration decreased the AD scenario benefits by $14 \%$, accentuating the predominance of the incineration scenario.

Choice of electricity substitution: In this consequential LCA, we assumed that the electricity production was marginal electricity produced from coal, emitting $1.042 \mathrm{~kg} \mathrm{CO}_{2}$-eq/kWh. Both scenarios were tested with a marginal electricity production in natural gas CHP plants with steam turbine emitting $0.616 \mathrm{~kg} \mathrm{CO}$-eq/kWh. Benefits of the two scenarios decreased: $-25 \%$ for the incineration scenario and $-39 \%$ for the AD scenario.

Choice of heat production: In the two scenarios heat production was modelled as substituting for heat production at a coal-fired CHP plant. The allocation between electricity and heat production at the CHP plant was based on exergy, so the substituted heat production had low carbon emissions: $0.194 \mathrm{~kg} \mathrm{CO}_{2}$-eq/kWh. A high carbon-emitting heat production was modelled to observe the effects on the two scenarios' GWF. A heat production at a hard coal industrial furnace emitting $0.472 \mathrm{~kg} \mathrm{CO}_{2}-\mathrm{eq} / \mathrm{kWh}$ was used. The incineration scenario obtained $77 \%$ more benefits and the AD scenario $35 \%$ more because the incineration plant recovered more heat than the AD plant. This choice changes the results significantly but does not change the scenario ranking. 
Choice of material substitution: Another process of the EASEWASTE database was tested for the substituted

511 production of nitrogen fertilizer. The original fertilizer production process emitted $15.33 \mathrm{~kg} \mathrm{CO}_{2}$-eq $/ \mathrm{kg} \mathrm{N}$ while the

512

513

514

515 second one emitted 16.34. The net benefit of the AD scenario increased by $1.4 \%$, which did not modify the scenario ranking.

Choice of incineration process: The incineration plant used to represent incineration in Denmark was based on data from the plant located in Aarhus. To observe the impacts of this choice, another incineration plant, located in Copenhagen, was used. This plant is a grate incinerator with wet flue gas cleaning and has $17.9 \%$ electricity and $78 \%$ heat recovery based on the waste LHV. The benefits of the incineration scenario decreased from -357 to $-272 \mathrm{~kg}$ $\mathrm{CO}_{2}$-eq/t waste, due to both lower electricity substitution and higher energy and material consumptions in the plant.

Choice of AD plant: The anaerobic digestion could as well be changed to examine the influence of this choice on the results. However this treatment is parameterized to a great extent in the EASEWASTE model, using potential methane yields for each material fraction as well as the content of methane in biogas and the energy recoveries of the gas engine. As all parameters were tested in the perturbation analysis this change of technology was not tested.

Finally the contribution analysis showed that the treatment of bottom ashes and APC residues did not have a significant impact on the GWF so no other option was studied for these residues. Minor material productions were also discarded for the same reasons. The inclusion of capital goods could not be assessed due to lack of data.

\subsubsection{Combined sensitivity analysis}

The water content and heating value (of dry matter) were chosen to perform the combined sensitivity analysis. Variations of these two parameters within chosen intervals were implemented and the difference between the AD and the incineration scenario computed. The contour lines $\left(50 \mathrm{~kg} \mathrm{CO}_{2}\right.$-eq/t) are presented in Figure 6 . The cross shows the initial conditions for which incineration is favourable. If both parameters are varied, the relative benefits s change and a shift of ranking between the two options can be visualized.

\subsection{Results of uncertainty propagation}

\subsubsection{Choice of representation}

For the purpose of stochastic modelling, probability distributions were selected for each model parameter. As the purpose of this case study was to illustrate the different methods, these statistical parameters were mainly based on expert judgement. They are presented in Table 2. Section 3.3.1 discusses how other tools that are better suited for 
representing expert judgement than single probability distributions, can be implemented in the uncertainty propagation.

For consumptions of materials and energy as well as for emissions, log-normal distributions were adopted, as they exclude negative value. For these parameters, geometric standard deviations were assumed using a method adapted from Frischknecht et al. (2005). The other parameters are waste properties and technical parameters of the plants, such as methane yields and electricity recoveries, for which normal distributions were selected. Two parameters reflect the uncertainty of the distribution between waste fractions. While all parameter uncertainties were assumed to be independent, it is acknowledged here that the heating value and methane potential could be partially correlated when considering biowaste. Finally, the uncertainties on methane potential and yield were applied only to the two biowaste fractions (vegetable and animal) which contribute to more than $95 \%$ of the total methane production of the source-separated organic waste.

\subsubsection{Uncertainty propagation for all scenarios}

The 24 parameters obtaining a SR higher than 0.05 in the perturbation analysis were implemented in a Monte Carlo calculation with 10000 iterations. Figure 4 presents results as relative frequency histograms as well as cumulative relative frequency plots.

The histogram in Figure 4a distributes the calculated GWF relative frequencies between bins of $25 \mathrm{~kg} \mathrm{CO}_{2^{-}}$ eq/t. This is useful for visualising the spread of GWF values around their means. The GWF of the incineration scenario obtains a mean of $-359 \mathrm{~kg} \mathrm{CO}$-eq/t with a standard deviation of $104 \mathrm{~kg} / \mathrm{t}$, while the AD scenario obtains a mean of $-292 \mathrm{~kg} / \mathrm{t}$ with a standard deviation of $76 \mathrm{~kg} / \mathrm{t}$. The cumulative relative frequencies in Figure $4 \mathrm{~b}$ display the same results in a different form which allows the identification of percentiles. For example, as indicated by the dotted lines, the probability that the incineration scenario should obtain a benefit of at least $400 \mathrm{~kg} \mathrm{CO}$-eq/t is $34 \%$, while the probability is only $9 \%$ for the AD scenario. In a similar fashion, $95 \%$ confidence intervals can be determined with this plot: $[-570 ;-166]\left(\mathrm{kg} \mathrm{CO}_{2}\right.$-eq/t) for the incineration scenario and [-450; -154] for the AD scenario.

\subsubsection{Discernibility analysis}

The dispersed frequency diagrams obtained for both scenarios do not inform about the relative predominance of one option over the other, because several parameters were used in the two scenarios, e.g. the electricity system and the water content. Therefore a discernibility analysis was performed to compute the difference between the GWF of the $\mathrm{AD}$ and the incineration scenarios. The relative frequency histograms and the cumulative relative frequency plots are presented in Figure 5. The difference between the two scenarios is $67 \mathrm{~kg} \mathrm{CO}_{2}$-eq/t with a standard deviation of 74 
$\mathrm{kg} / \mathrm{t}$. Using the cumulative probability distribution, it can be observed that AD obtains more benefits than incineration in $18 \%$ of the cases.

\subsection{Uncertainty contribution analysis}

The contributions of the 24 parameter uncertainties to the overall uncertainty were calculated using both the analytical (using Equation 4) and the SC methods (using Equation 5), for the two scenarios and the difference between them. The results obtained by the two methods vary by less than 0.5 percentage points, confirming that the simpler SC method can be used as a good approximation of the contributions. It should be noted that the analysis was performed using Equation 3 even though some of the parameters were not symmetrically distributed and that the first order terms of the Taylor series produce only an approximation. Consequently the sum of all contributions never reaches $100 \%$.

The results obtained with the analytical method are presented in Table 3 . The water content appears to be predominant parameters with respect to uncertainty of the incineration (resp. AD) scenario are the heating value and the electricity recovery (resp. methane content, yield and electricity recovery) because they determine the energy recovery of each treatment.

With respect to the final decision, the three most predominant parameters are the heating value and water importance.

\section{Discussion}

Seven methods for quantifying the uncertainty of LCA results have been selected and applied in a comparative study of two waste management systems. This study was reduced to two scenarios and one impact category but it led to more general findings presented in this section. The presented study provides valuable insight into the possibilities offered by each method as well as its limitations and the difficulties of implementation. Based on the complementarities of these methods, as illustrated by the case study, we suggest that a tiered approach be used for quantitative uncertainty assessment of waste LCA. The general approach is illustrated in Figure 7. Following an introductory step (Step 0), the sequential approach contains four separate steps: (Step 1) evaluating the sensitivity of the result to each individual source of uncertainty, (Step 2) representing parameter uncertainty based on available 
information and calculating the uncertainty of the model's results, (Step 3) analysing the origins of this uncertainty, (Step 4) visualising the shift of scenario ranking due to combined variations of key parameters. These steps start from a coarse evaluation and evolve to achieve a more precise analysis of the uncertainty in each step. As the complexity of the calculations and the amount of data required increase, the analysis can be applied on a decreasing number of scenarios, impact categories or input uncertainties, in order to cope with resource limitations. In addition it should be kept in mind that model uncertainties can rarely be assessed quantitatively but should be considered. They can be accommodated by using several plausible alternative models and aggregating the results in a single restitution.

\section{Step 0: Contribution analysis}

This preliminary analysis should be performed on all scenarios and impact categories. All LCA results are disaggregated to visualize contributions of every process to loads and savings. However, this analysis does not provide any information on the sensitivity or the uncertainty of the results. Figure 1 provided an example of a contribution analysis.

\section{Step 1: Sensitivity analysis}

A proper sensitivity analysis should always be performed on as many input uncertainties as possible. The method suggests that parameter uncertainties are assessed by perturbation analysis (step 1a) comparing SR. Figure 2 provided an example of a perturbation analysis using SR. Model and scenario uncertainties should be analysed by scenario analysis (step 1b) and not propagated in a stochastic modelling. Figure 3 provided an example of a scenario analysis. This should be performed on all scenarios and as many impact categories as possible. It does not require extra data collection and gives valuable information on how the model and the scenarios react to variations in the input. Nevertheless it does not give any information on the uncertainty of the final result because it does not reflect the actual input uncertainties. Sensitivity analysis is very valuable to find where more data collection is needed, estimate the robustness of results and reduce the number of parameters for the uncertainty propagation.

\section{Step 2: Uncertainty propagation}

The choice of representation is of primary importance since the uncertainty in model results depends largely on the uncertainties assigned to input parameters and scenarios (Step 2a). In this paper, we suggest adopting probabilistic modelling techniques, that are widely used. The shortcomings of these methods in a context of incomplete information have been referred to in section 3.3.1 and are currently being addressed in ongoing research. As shown in the case study, if single probability distributions are assumed for all uncertain parameters, a Monte Carlo analysis can be used to propagate these uncertainties into that of the model results. This analysis 
provides the modeller with the uncertainty relative to each scenario's results through parameter uncertainty propagation (Step 2b). The uncertainty of the final decision is obtained by considering the difference between two alternative scenarios in the discernibility analysis (Step 2c). Considering the amount of data required in order to inform the uncertainties pertaining to input parameters, it is recommended to use the results of the sensitivity analysis to reduce the number of uncertainties implemented in the uncertainty propagation. The number of scenarios and impact categories investigated can also be reduced to the most critical ones.

Results of both steps can be presented as relative frequency histograms and cumulative relative frequencies. Figures 4 and 5 provided an example of an uncertainty propagation using a Monte Carlo analysis. Results of the discernibility analysis (step 2c) might be easier to communicate by presenting only the percentage of cases where one option obtains more favourable results than the other, especially if there are more than two scenarios.

\section{Step 3: Uncertainty contribution analysis}

This analysis tells us which parameter uncertainties are the most important and can help prioritize further efforts in data collection. The contribution of each parameter's uncertainty to the overall uncertainty can be easily approximated with Equation 5 using results of steps 1a and 2a. Table 3 showed the result of an uncertainty contribution analysis.

\section{Step 4: Combined sensitivity analysis}

This analysis illustrates the conditions under which one attractive scenario is favoured with respect to another attractive scenario. An example of this result was presented in Figure 6. The result of this analysis is relatively easy to communicate and comparisons between more than two scenarios can be performed by adding more plots in the same figure. However only two parameters can be varied at a time. Finally, implementation of this analysis requires additional resources, either to parameterize the results or to run a large number of simulations.

The proposed sequential method for quantitative uncertainty assessment should be applied to all waste-LCA studies. However, it can be reduced to steps 0 and 1 if time and available resources are limited, because these steps only require an LCA model and no additional data. To implement waste properties and composition, the use of a dedicated tool for waste management, e.g. the EASEWASTE model, is recommended because parameters can be changed easily. For example, the definition of biogas production potentials of different waste fractions is facilitated in a dedicated waste-LCA model. Step 2 requires the use of additional features to implement a Monte Carlo analysis. This has already been implemented in some LCA models. Then step 3 can easily be implemented by using results from steps 1 and 2. Finally step 4 requires substantial additional resources. 


\section{Conclusions}

671

672 LCA of waste management is subject to significant sources of uncertainty of diverse origins. In order to improve the 673 reliability of the results, uncertainties must be addressed in a systematic and quantitative fashion. We described, 674 based on a decade of experience, where the main uncertainties can be found within LCA -modelling of waste management systems. A systematic sequential method to evaluate uncertainty in LCA studies of waste management systems has been suggested and exemplified. It includes four steps with increasing calculation complexity and data requirement. Modellers can adapt this method to their resources and should first focus on their requirements to choose the right tools. It has been recognized in this paper that in real-world situations of waste LCAs, the modeller is typically confronted with different types of information regarding parameter uncertainties. The information might be "rich"

681 (when a significant number of measurements are available), in which case a statistical analysis of the data can 682 provide probability distributions describing parameter variability, or the information can be "poor" (when expert 683 judgement, literature data, scarce measurements or gross estimates have to be used), in which case alternative 684 uncertainty-representation tools may seem more consistent with available information (e.g. fuzzy sets and probability 685 boxes). As shown previously by e.g. Baudrit et al. (2006) and Dubois and Guyonnet (2011), different modes of 686 uncertainty representation can be propagated jointly in model calculations. Hence forthcoming research will focus on 687 how such methods can be applied to uncertainty representation and propagation in waste LCAs. This will avoid the 688 arbitrary assignment of single probability distributions in presence of incomplete information and hence the common 689 confusion between stochastic and epistemic uncertainties.

690 


\section{References}

Baudrit, C., Dubois, D., Guyonnet, D., 2006. Joint propagation and exploitation of probabilistic and possibilistic information in risk assessment models. IEEE Transactions on Fuzzy Systems 14, 593-608.

695

Benetto, E., Dujet, C., Rousseaux, P, 2006. Possibility Theory: A New Approach to Uncertainty Analysis?

Benetto, E., Dujet, C., Rousseaux, P, 2008. Integrating fuzzy multicriteria analysis and uncertainty evaluation in life cycle assessment. Environmental Modelling \& Software 23, 1461-1467.

Björklund, A., Finnveden, G., 2005. Recycling revisited - life cycle comparisons of global warming impact and total energy use of waste management strategies. Resources, Conservation and Recycling 44, 309-317.

Boldrin, A., Hartling, K.R., Laugen, M., Christensen, T.H., 2010. Environmental inventory modelling of the use of compost and peat in growth media preparation. Resources, Conservation and Recycling 54, 1250-1260.

Boldrin, A., Neidel, T.L., Damgaard, A., Bhander, G.S., Møller, J., Christensen, T.H., 2011. Modelling of environmental impacts from biological treatment of organic municipal waste in EASEWASTE presents the biological treatment module. Waste Management 31, 619-630.

Bovea, M.D., Ibáñez-Forés, V., Gallardo, A., Colomer-Mendoza, F.J., 2010. Environmental assessment of alternative municipal solid waste management strategies. A Spanish case study. Waste Management 30, 2383-2395.

Bruun, S., Hansen, T.H., Christensen, T.H., Magid, J., Jensen, L.S., 2006. Application of processed organic municipal solid waste on agricultural land - a scenario analysis. Environmental Modeling and Assessment 11, 251265.

Cherubini, F., Strømman, A.H., Ulgiati, S., 2011. Influence of allocation methods on the environmental performance of biorefinery products-A case study. Resources conservation and recycling 55, 1070-1077. 
Chevalier, J.-L., Le Téno, J.-F., 1996. Life cycle analysis with ill-defined data and its application to building products. International Journal of Life Cycle Assessment 1, 90-96.

Christensen, T.H., Bhander, G., Lindvall, H., Larsen, A.W., Fruergaard, T., Damgaard, A., Manfredi, S., Boldrin, A., Riber, C., Hauschild, M., 2007. Experience with the use of LCA-modelling (EASEWASTE) in waste management. Waste Management Research 25, 257-262.

Christensen, T.H., Gentil, E., Boldrin, A., Larsen, A.W., 2009. C balance, carbon dioxide emissions and global warming potentials in LCA-modelling of waste management systems. Waste Management Research 27, 707-715.

Connover, W., Iman, R., 1982. A distribution-free approach to inducing rank correlation among input variables. Technometric 3, 311-334.

Damgaard, A., Manfredi, S., Merrild, H., Stensøe, S., Christensen, T.H., 2011. LCA and economic evaluation of landfill leachate and gas technologies. Waste Management 31, 1532-1541.

Dubois, D., Prade, H., 1988. Possibility Theory: An Approach to Computerized Processing of Uncertainty. Plenum Press, New York.

Dubois, D., Guyonnet, D., 2011. Risk-informed decision-making in the presence of epistemic uncertainty. International Journal of General Systems 40, 145-167.

Ekvall, T., Assefa, G., Björklund, A., Eriksson, O., Finnveden, G., 2007. What life-cycle assessment does and does not do in assessments of waste management. Waste Management 27, 989-996.

Ferson, S., Ginzburg, L.R., 1996. Different methods are needed to propagate ignorance and variability. Reliability Engineering and Systems Safety 54, 133-144.

Finnveden, G., Johansson, J., Lind, P., Moberg, G., 2005. Life cycle assessment of energy from solid waste-part 1: general methodology and results. Journal of Cleaner Production 13, 213-229. 
Finnveden, G., Nilsson, M., 2005. Site-dependent Life-Cycle Impact Assessment in Sweden. International Journal of Life Cycle Assessment 10, 235 - 239.

Finnveden, G., Hauschild, M.Z., Ekvall, T., Guinée, J., Heijungs, R., Hellweg, S., Koehler, A., Pennington, D., Suh, S., 2009. Recent developments in Life Cycle Assessment. Journal of Environmental Management 91, 1-21.

Forster, P., Ramaswamy, V., Artaxo, P., Berntsen, T., Betts, R., Fahey, D.W., Haywood, J., Lean, J., Lowe, D.C., Myhre, G., Nganga, J., Prinn, R., Raga, G., Schulz, M., Van Dorland, R., 2007. Changes in Atmospheric Constituents and in Radiative Forcing. In: Climate Change 2007: The Physical Science Basis. Contribution of Working Group I to the Fourth Assessment Report of the Intergovernmental Panel on Climate Change [Solomon, S., D. Qin, M. Manning, Z. Chen, M. Marquis, K.B. Averyt, M.Tignor and H.L. Miller (eds.)]. Cambridge University Press, Cambridge, United Kingdom and New York, NY, USA.

Frischknecht, R., Jungbluth, N., Althaus, H.J., Doka, G., Dones, R., Heck, T.,

Hellweg, S., Hischier, R., Nemecek, T., Rebitzer, G., Spielmann, M., 2005. The ecoinvent Database: Overview and Methodological Framework. International Journal of Life Cycle Assessment 10, 3 - 9.

Frischknecht, R., Althaus, H.J., Bauer, C., Doka, G., Heck, T., Jungbluth, N., Kellenberger, D., Nemecek, T., 2007. The Environmental Relevance of Capital Goods in Life Cycle Assessments of Products and Services. International Journal of Life Cycle Assessment 12, 7-17.

Gentil, E., Clavreul, J., Christensen, T.H., 2009. Global warming factor of MSW management in Europe. Waste Management Research 27, 850-860.

Gentil, E., Damgaard, A., Hauschild, M., Finnveden, G., Eriksson, O., Thorneloe, S., Kaplan, P.O., Barlaz, M., Muller, O., Matsui, Y., Ii, R., Christensen, T.H., 2010. Models for waste life cycle assessment: Review of technical assumptions. Waste Management 30, 2636-2648.

Hansen, T.L., Christensen, T.H., Schmidt, S., 2006. Environmental modelling of use of treated organic waste on agricultural land: a comparison of existing models for life cycle assessment of waste systems. Waste Management Research 24, 141-152. 
Hauschild, M., Olsen, S. I., Hansen, E., Schmidt, A., 2008. Gone... but not away — addressing the problem of longterm impacts from landfills in LCA. International Journal of Life Cycle Assessment 13, 547-554.

Heijungs, R., Kleijn, R., 2001. Numerical approaches towards life cycle interpretation - Five examples. International Journal of Life Cycle Assessment 6, 141 - 148.

Heijungs, R., Suh, S., Kleijn, R., 2005. Numerical approaches to life cycle interpretation - The case of the ecoinvent 96 database. International Journal of Life Cycle Assessment 10, 103 - 112.

Heijungs, R., Tan, R. R., 2010. Rigorous proof of fuzzy error propagation with matrix-based LCI. International Journal of Life Cycle Assessment 15, 1014-1019.

Hoffman, F.O., Hammonds, J.S., 1994. Propagation of uncertainty in risk assessments: the need to distinguish between uncertainty due to lack of knowledge and uncertainty due to variability. Risk Analysis 14, 707-712.

Hong, J., Shaked, S., Rosenbaum, R.K., Jolliet, O., 2010. Analytical uncertainty propagation in life cycle inventory and impact assessment: application to an automobile front panel. International Journal of Life Cycle Assessment 15, 499-510.

Huijbregts, M.A.J., 1998. Application of uncertainty and variability in LCA, A general framework for the analysis of uncertainty and variability in life cycle assessment. International Journal of Life Cycle Assessment 3, $273-280$.

Huijbregts, M. A. J., Gilijamse, W., Ragas, A. M. J., Reijnders, L., 2003. Evaluating uncertainty in environmental life-cycle assessment. A case study comparing two insulation options for a Dutch one-family dwelling.

Environmental Science \& Technology 37, 2600-8.

IPCC, 2006. 2006. IPCC Guidelines for National Greenhouse Gas Inventories, Prepared by the National Greenhouse Gas Inventories Programme, Eggleston H.S., Buendia L., Miwa K., Ngara T. and Tanabe K. (eds). IGES, Japan.

ISO, 2006. ISO 14040: environmental management - life cycle assessment - principles and framework. ISO 14040 :2006(E), International Standards Organisation. 
Kaplan, P. O., Ranjithan, S. R., Barlaz, M. A., 2009. Use of life-cycle analysis to support solid waste management

818 planning for Delaware. Environmental Science \& Technology 43, 1264-1270.

819

820 Kirkeby, J.T., Birgisdóttir, H., Hansen, T.L., Christensen, T.H., Bhander, G.S., Hauschild, M.Z., 2006.

821 Environmental assessment of solid waste systems and technologies: EASEWASTE. Waste Management Research $822 \quad 24,3-15$.

Lazarevic, D., Aoustin, E., Buclet, N., Brandt, N., 2010. Plastic waste management in the context of a European recycling society: Comparing results and uncertainties in a life cycle perspective. Resources, Conservation and Recycling 55, 246-259.

Lenzen, M., Treloar, G., 2003. Differential convergence of life-cycle inventories toward upstream production layers. Journal of Industrial Ecology 6, 137-160.

Lloyd, S. M., Ries, R., 2007. Characterizing, propagating, and analyzing uncertainty in life-cycle assessment, a survey of quantitative approaches. Journal of Industrial Ecology 11, 161-179.

Lo, S.-C., Ma, H.-W., Lo, S.-L., 2004. Quantifying and reducing uncertainty in life cycle assessment using the Bayesian Monte Carlo method. Science of the Total Environment 340, 23-33.

Manfredi, S., Christensen, T.H., 2009. Environmental assessment of solid waste landfilling technologies by means of LCA-modeling. Waste Management 29, 32-43.

Merrild, H., Damgaard, A., Christensen, T.H., 2008. Life cycle assessment of waste paper management: The importance of technology data and system boundaries in assessing recycling and incineration. Resources Conservation and Recycling 52, 1391-1398.

Morgan, M.G., Henrion, M., 1990. Uncertainty: a guide to dealing with uncertainty in quantitative risk and policy 
Møller J., Jansen J. La Cour, Christensen, T.H., 2010. Digestion: Mass balances and products. In: Christensen, T.H. (ed.) Solid Waste Management and Technologies. John Wiley \& Sons Ltd, Chichester, UK.

Petersen, C., Domela, I., 2003. Sammensætning af dagrenovation og ordninger for hjemmekompostering. Miljøprojekt nr. 868 2003. Miljøstyrelsen, Miljøministeriet. København.

Pires, A., Chang, N-B., Martinho, G., 2011. Reliability-based life cycle assessment for future solid waste management alternatives in Portugal. International Journal of Life Cycle Assessment 16, 316-337.

Pizzol, M., Christensen, P., Schmidt, J., Thomsen, M., 2011a. Impacts of "metals” on human health: a comparison between nine different methodologies for Life Cycle Impact Assessment (LCIA). Journal of Cleaner Production 19, 646-656.

Pizzol, M., Christensen, P., Schmidt, J., Thomsen, M., 2011b. Eco-toxicological impact of "metals" on the aquatic and terrestrial ecosystem: A comparison between eight different methodologies for Life Cycle Impact Assessment (LCIA). Journal of Cleaner Production 19, 687-698.

Ramaswamy, V., Boucher, O., Haigh, J., Hauglustaine, D., Haywood, J., Myhre, G., Nakajima, T., Shi, G.Y.,

Solomon, S., 2001. Radiative Forcing of Climate Change. In: Climate Change 2001: The Scientific Basis.

Contribution of Working Group I to the Third Assessment Report of the Intergovernmental Panel on Climate Change

[Houghton, J.T.,Y. Ding, D.J. Griggs, M. Noguer, P.J. van der Linden, X. Dai, K. Maskell, and C.A. Johnson (eds.)].

Reap, J., Roman, F., Duncan, S., Bras, B., 2008. A survey of unresolved problems in life cycle assessment, Part 1: goal and scope and inventory analysis. International Journal of Life Cycle Assessment 13, 290-300.

Riber, C., Christensen T. H., 2006a. Method for fractional solid waste sampling and chemical analysis. International Journal of Environmental Analytical Chemistry 87, 321-335. 
882 Saltelli, A., Ratto, M., Tarantola, S., Campolongo, F, 2006. Sensitivity analysis practices: Strategies for model-based 883 inference. Reliability Engineering \& System Safety 91, 1109-1125.

884

885 Savage, L., 1954. The foundations of statistics. New York. Wiley, (2nd Edition 1972, Dover).

886

Shafer, G. 1976. A Mathematical Theory of Evidence. Princeton University Press, Princeton, USA.

888

889 Sonnemann, G. W., Schuhmacher, M., Castells, F., 2003. Uncertainty assessment by a Monte Carlo simulation in a

890 life cycle inventory of electricity produced by a waste incinerator. Journal of Cleaner Production 11, 279-292.

891

892 Suh, S., Lenzen, M., Treloar, G.J., Hondo, H., Horvath, A., Huppes, G., Jolliet, O., Klann, U., Krewitt, W.,

893 Moriguchi, Y., Munksgaard, J., Norris, G., 2004. System boundaries in life-cycle inventories using hybrid

894 approaches. Environmental Science \& Technology 38, 657-664.

895

896 Toller, S., Kaarman, E., Gustafsson, J.P., Magnusson, Y., 2009. Environmental assessment of incinerator residue

897 utilisation. Waste Management 29, 2071-2077.

898

899 Walley, P., 1991. Statistical reasoning with imprecise probabilities. Chapman and Hall, London, UK.

900

901 Williams, E., Weber, C., Hawkins, T., 2009. Hybrid Approach to Managing Uncertainty in Life Cycle Inventories.

902 Journal of Industrial Ecology 15, 928-944.

903 
Table 1: Uncertainties in LCA of waste management systems

\begin{tabular}{|c|c|c|c|}
\hline Process & Model uncertainty & Scenario uncertainty & Parameter uncertainty \\
\hline General & $\begin{array}{l}\text { Linearity of emissions } \\
\text { Modelling of waste- and process- } \\
\text { specific emissions }\end{array}$ & $\begin{array}{l}\text { System boundaries } \\
\text { Database for energy and material } \\
\text { productions (e.g. Ecoinvent) } \\
\text { Time horizon of inventories } \\
\text { Allocation }\end{array}$ & \\
\hline $\begin{array}{l}\text { Impact } \\
\text { assessment }\end{array}$ & $\begin{array}{l}\text { Model for substances' fate and effects } \\
\text { to calculate characterisation factors. } \\
\text { Linearity of response }\end{array}$ & $\begin{array}{l}\text { Time horizon of impact } \\
\text { characterisation } \\
\text { Normalization method and reference } \\
\text { Weighting method and reference }\end{array}$ & Characterisation factors \\
\hline $\begin{array}{l}\text { Waste } \\
\text { composition }\end{array}$ & & $\begin{array}{l}\text { Choice of a specific waste } \\
\text { composition }\end{array}$ & $\begin{array}{l}\text { Waste fractions distribution; chemical } \\
\text { composition of fractions (e.g. water } \\
\text { content; heating value) }\end{array}$ \\
\hline Collection & Model for collection & $\begin{array}{l}\text { Choice of a collection scheme (e.g. } \\
\text { separate or common collection) }\end{array}$ & $\begin{array}{l}\text { Consumption of fuel; emissions from } \\
\text { fuel combustion; } \\
\text { source-sorting efficiencies }\end{array}$ \\
\hline Transport & & & $\begin{array}{l}\text { Distance; consumption of fuel; } \\
\text { emissions from fuel combustion }\end{array}$ \\
\hline $\begin{array}{l}\text { Material } \\
\text { recovery facility }\end{array}$ & & Choice of a specific technology & $\begin{array}{l}\text { Sorting efficiencies; consumption of } \\
\text { materials and energy }\end{array}$ \\
\hline $\begin{array}{l}\text { Thermal } \\
\text { treatment }\end{array}$ & & $\begin{array}{l}\text { Choice of a specific technology (e.g. } \\
\text { dry/wet flue gas cleaning with } \\
\text { SCR/SNCR) } \\
\text { Choice of specific technologies for } \\
\text { outputs' treatments }\end{array}$ & $\begin{array}{l}\text { Electricity and heat recoveries; } \\
\text { consumption of materials and energy; } \\
\text { emissions of substances to outputs and } \\
\text { environment; water content of } \\
\text { produced ashes; consumption of } \\
\text { materials and energy for outputs' } \\
\text { treatments }\end{array}$ \\
\hline $\begin{array}{l}\text { Biological } \\
\text { treatment }\end{array}$ & $\begin{array}{l}\text { Model for biodegradation (e.g. based } \\
\text { on } \mathrm{CH}_{4} \text {-potential or on hemi-celluloid } \\
\text { material) and } \mathrm{CH}_{4} / \mathrm{CO}_{2} \text { ratio in biogas }\end{array}$ & Choice of a specific technology & $\begin{array}{l}\text { Degradation rates of organic matter; } \\
\text { nitrogen distribution; gas cleaning } \\
\text { removal efficiencies; composition of } \\
\text { biogas }\left(\mathrm{CH}_{4} / \mathrm{CO}_{2}\right) \text {; consumption of } \\
\text { materials and energy; emissions of } \\
\mathrm{CH}_{4} \text { and energy recovery in gas engine }\end{array}$ \\
\hline Use on land & $\begin{array}{l}\text { Model for plant uptakes and fertilizer } \\
\text { substitution } \\
\text { Model for leaching }\end{array}$ & $\begin{array}{l}\text { Choice of a specific technology (e.g. } \\
\text { on sandy or loamy soil) }\end{array}$ & $\begin{array}{l}\text { Substitution rate of compost / } \\
\text { fertilizers (\%); carbon binding (\%); } \\
\text { distribution of N; run-off; leaching }\end{array}$ \\
\hline Landfill & $\begin{array}{l}\text { Model for gas generation } \\
\text { Model for leachate generation and } \\
\text { leaching to groundwater }\end{array}$ & $\begin{array}{l}\text { Choice of a specific technology (e.g. } \\
\text { conventional or bioreactor) } \\
\text { Choice of gas utilization } \\
\text { Choice of a technology for leachate } \\
\text { treatment }\end{array}$ & $\begin{array}{l}\text { Gas composition (elements; } \mathrm{CH}_{4} \text {, } \\
\mathrm{CO}_{2} \text { ); collection, utilization and } \\
\text { oxidation rates; leachate composition, } \\
\text { collection rate; removal efficiencies at } \\
\text { leachate treatment; consumption of } \\
\text { materials and energy; emissions and } \\
\text { energy recovery of gas engine }\end{array}$ \\
\hline Recycling & & $\begin{array}{l}\text { Choice of specific technologies for the } \\
\text { recycling plant and the avoided } \\
\text { material production }\end{array}$ & $\begin{array}{l}\text { Substitution rate; consumption of } \\
\text { materials and energy of recycling } \\
\text { plant and substituted process }\end{array}$ \\
\hline
\end{tabular}


Table 2: Assumed probability distributions of parameters used in the case study (AD: anaerobic digestion, UOL: use

909 on land, TS: total solid, ww: wet weight, VS: volatile solids, LHV: lower heating value, GHG: greenhouse gas)

\begin{tabular}{|c|c|c|c|c|}
\hline Parameter & Mean $^{a}$ & Unit & Distribution & $\begin{array}{l}\text { St. dev. or GSD' } \\
\text { or half-width }\end{array}$ \\
\hline Ratio of vegetable out of food waste & 76.1 & $\%$ & Normal & 6 \\
\hline Part of plastic fraction in waste & 1.12 & $\%$ & Normal & 0.25 \\
\hline Water content of waste & 67.1 & $\% \mathrm{ww}$ & Normal & 4 \\
\hline Heating value of dry waste & 19.21 & $\mathrm{MJ} / \mathrm{kg} \mathrm{TS}$ & Normal & 1 \\
\hline Methane potential of waste & 450 & $\mathrm{~m} 3 \mathrm{CH}_{4} / \mathrm{t} \mathrm{VS}$ & Normal & 30 \\
\hline Diesel consumption for collection of organic waste & 7.2 & $\mathrm{~L} / \mathrm{t}$ & Log-normal & 1.16 \\
\hline Distance from digester to use on land & 30 & $\mathrm{~km}$ & Log-normal & 2.33 \\
\hline GHG emissions of diesel production & 3.108 & $\mathrm{~kg} \mathrm{CO}_{2}$-eq / L & Log-normal & 1.14 \\
\hline Electricity consumption of incineration & 65.7 & $\mathrm{kWh} / \mathrm{t}$ & Log-normal & 1.10 \\
\hline Electricity recovery of incineration & 20.7 & $\%$ of LHV & Normal & 2 \\
\hline Heat recovery of incineration & 74 & $\%$ of LHV & Normal & 5 \\
\hline $\mathrm{CH}_{4}$ content of biogas in digester & 63 & $\%$ & Normal & 3 \\
\hline Electricity consumption of digester & 48.9 & $\mathrm{kWh} / \mathrm{t}$ & Log-normal & 1.10 \\
\hline Electricity recovery from gas in digester & 39 & $\%$ & Normal & 2 \\
\hline Heat recovery from gas in digester & 46 & $\%$ & Normal & 4 \\
\hline Methane potential yield in digester & 80 & $\%$ & Normal & 5 \\
\hline Unburnt methane in digester & 2 & $\%$ & Log-normal & 1.10 \\
\hline Water content of digestate & 3 & $\%$ of ww & Uniform & 2 \\
\hline Carbon binding in soil & 13 & $\%$ of $\mathrm{C}$ & Normal & 2 \\
\hline $\mathrm{N}$ fertilizer substitution & 40 & $\%$ of $\mathrm{N}$ & Uniform & 10 \\
\hline GHG emissions from $\mathrm{N}$ fertilizer production & 15.33 & $\mathrm{~kg} \mathrm{CO}$-eq / kg & Log-normal & 1.23 \\
\hline $\mathrm{N}_{2} \mathrm{O}$ emissions from use on land & 1.4 & $\%$ of $\mathrm{N}$ in digestate & Log-normal & 1.43 \\
\hline GHG emissions of electricity system & 1.042 & $\mathrm{~kg} \mathrm{CO}$-eq / kWh & Log-normal & 1.07 \\
\hline GHG emissions of heat system & 0.194 & $\mathrm{~kg} \mathrm{CO}$-eq / kWh & Log-normal & 1.12 \\
\hline
\end{tabular}

$910 \quad{ }^{\mathrm{a}}$ : Geometrical mean for lognormal distributions

911 b: Standard deviation for normal distributions, square of geometric standard deviation for lognormal distributions,

912 half of the width of the interval for uniform distributions 
914 Table 3: Contribution of each parameter uncertainty to the uncertainties of each scenario and to the difference

915 between them, obtained with the analytical method

\begin{tabular}{|c|c|c|c|}
\hline Parameter & $\begin{array}{c}\text { Incineration } \\
\text { scenario }\end{array}$ & $\begin{array}{l}\text { Anaerobic } \\
\text { digestion } \\
\text { scenario }\end{array}$ & $\begin{array}{l}\text { Difference } \\
\text { between } \\
\text { scenarios }\end{array}$ \\
\hline Ratio of vegetable out of food waste & $9.9 \%$ & $4.6 \%$ & $4.9 \%$ \\
\hline Part of plastic fraction in waste & $0.0 \%$ & $0.0 \%$ & $0.0 \%$ \\
\hline Water content of waste & $66.5 \%$ & $56.4 \%$ & $14.0 \%$ \\
\hline Heating value of dry waste & $10.4 \%$ & - & $20.5 \%$ \\
\hline Methane potential of waste & - & $9 \%$ & $9.5 \%$ \\
\hline Diesel consumption for collection of organic waste & - & $0.0 \%$ & $0.1 \%$ \\
\hline Distance from digester to use on land & - & $1.4 \%$ & $1.5 \%$ \\
\hline GHG emissions of diesel production & - & $0.3 \%$ & $0.2 \%$ \\
\hline Electricity consumption of incineration & $0.1 \%$ & - & $0.2 \%$ \\
\hline Electricity recovery of incineration & $7.2 \%$ & - & $14.2 \%$ \\
\hline Heat recovery of incineration & $1.6 \%$ & - & $3.1 \%$ \\
\hline $\mathrm{CH}_{4}$ content of biogas in digester & - & $0.0 \%$ & $0.0 \%$ \\
\hline Electricity consumption of digester & - & $0.1 \%$ & $0.1 \%$ \\
\hline Electricity recovery from gas in digester & - & $4.8 \%$ & $5.1 \%$ \\
\hline Heat recovery from gas in digester & - & $0.7 \%$ & $0.7 \%$ \\
\hline Methane potential yield in digester & - & $7.9 \%$ & $8.4 \%$ \\
\hline Unburnt methane in digester & - & $0.1 \%$ & $0.1 \%$ \\
\hline Water content of digestate & - & $2.4 \%$ & $2.5 \%$ \\
\hline Carbon binding in soil & - & $0.7 \%$ & $0.7 \%$ \\
\hline $\mathrm{N}$ fertilizer substitution & - & $1.3 \%$ & $1.4 \%$ \\
\hline GHG emissions from $\mathrm{N}$ fertilizer production & - & $0.7 \%$ & $0.7 \%$ \\
\hline $\mathrm{N}_{2} \mathrm{O}$ emissions from use on land & - & $2.4 \%$ & $2.5 \%$ \\
\hline GHG emissions of electricity system & $0.5 \%$ & $1.5 \%$ & $0.1 \%$ \\
\hline GHG emissions from heat system & $1.1 \%$ & $0.3 \%$ & $0.9 \%$ \\
\hline
\end{tabular}

916 


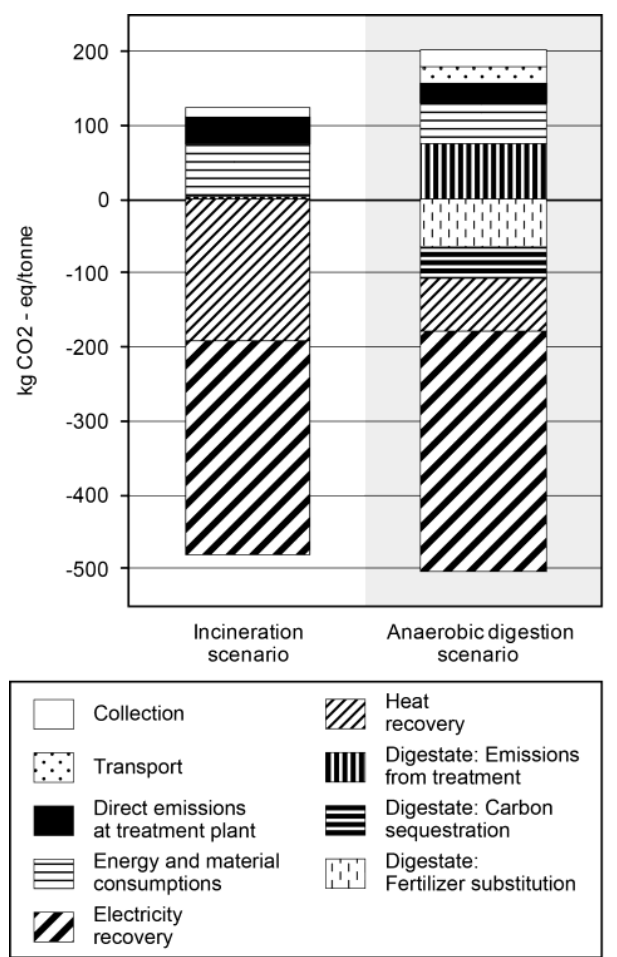

Figure 1: Contribution analysis of the global warming factors of the two scenarios. Rejects refers to ashes for the incineration scenario and to digestate for the anaerobic digestion scenario. a. Sensitivity ratios for the incineration scenario

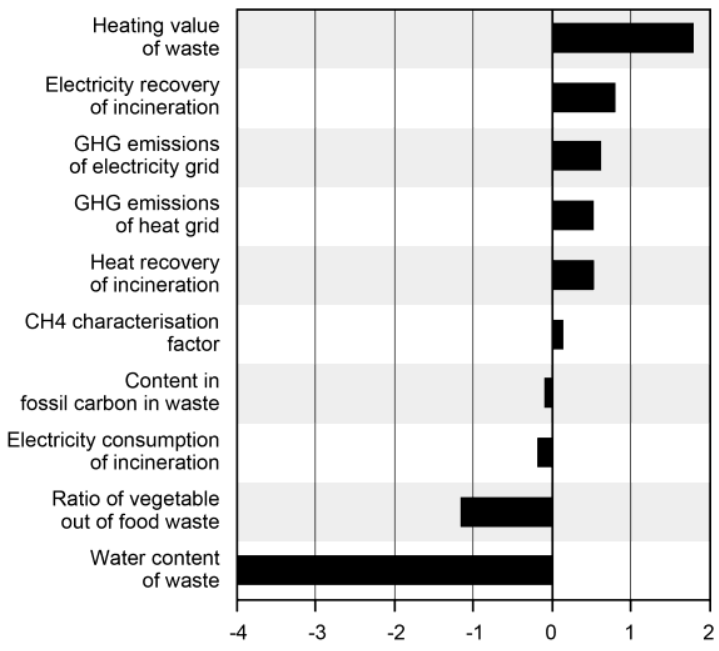

b. Sensitivity ratios for the anaerobic digestion scenario

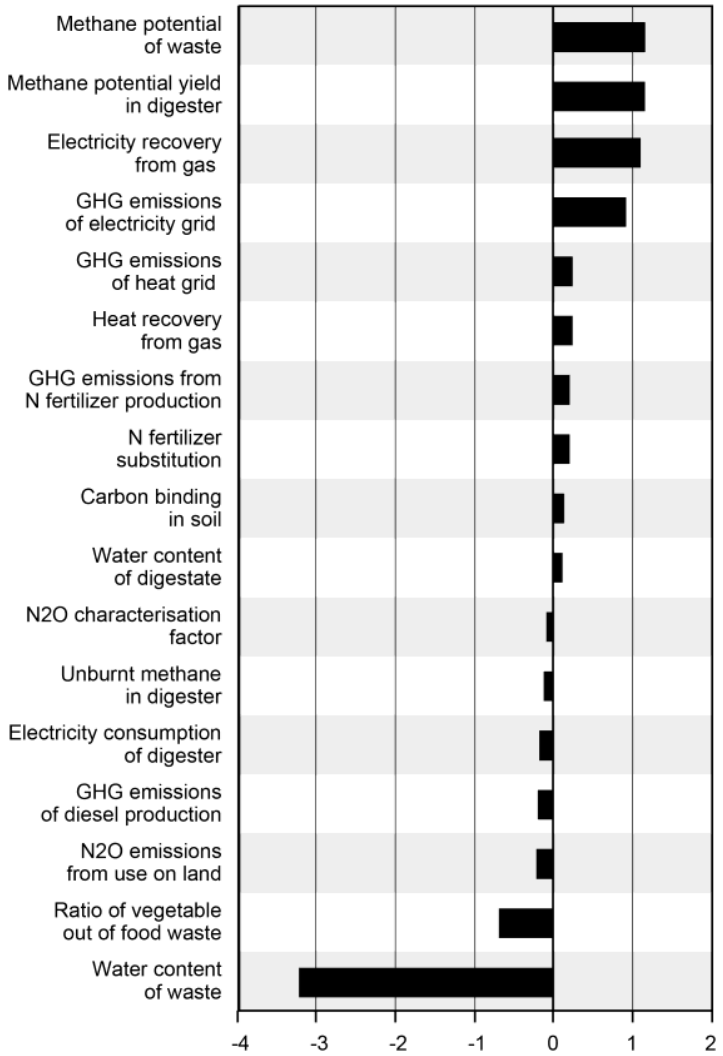

Figure 2: Parameter sensitivity ratios with respect to global warming factors of the incineration and the anaerobic digestion scenarios. Only sensitivity ratios greater than 0.1 as absolute value are presented (GHG: greenhouse gases). 


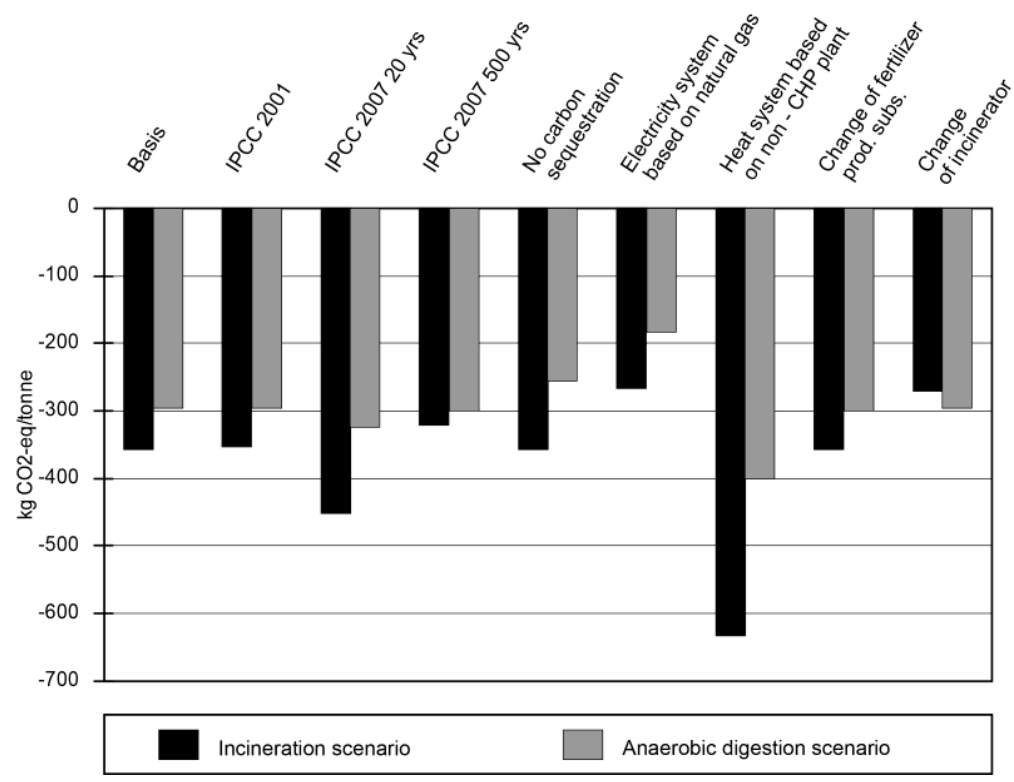

921

922 Figure 3: Global warming factors obtained for the two scenarios when implementing different choices in the 923 scenario analysis.

924 

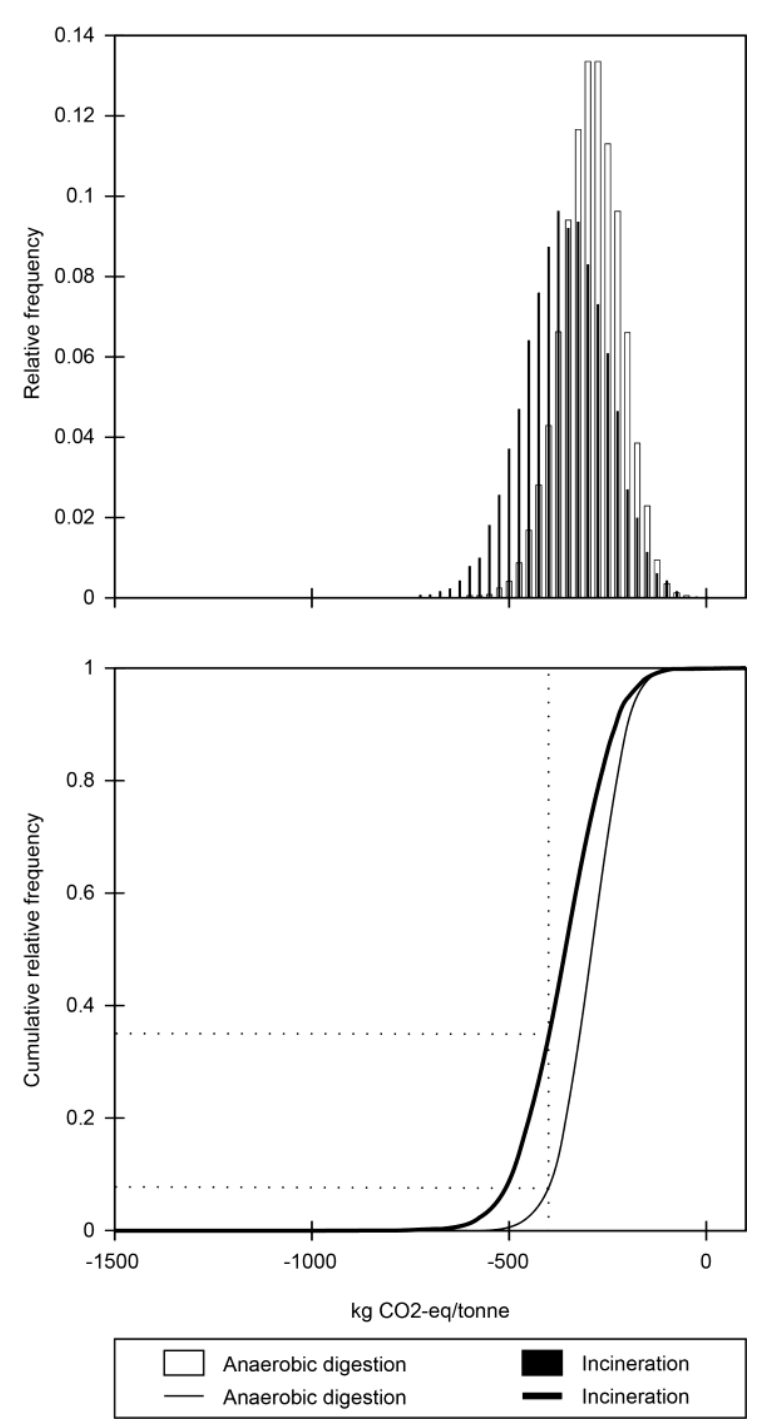

Figure 4: Relative frequency histograms and cumulative relative frequency distributions for the global warming factors of the two scenarios. The dotted lines indicate the percentiles of cases achieving a benefit of more than 400 $\mathrm{kg} \mathrm{CO}_{2}$-eq /t in both cases, i.e. a global warming factor lower than $-400 \mathrm{~kg} / \mathrm{t}$.
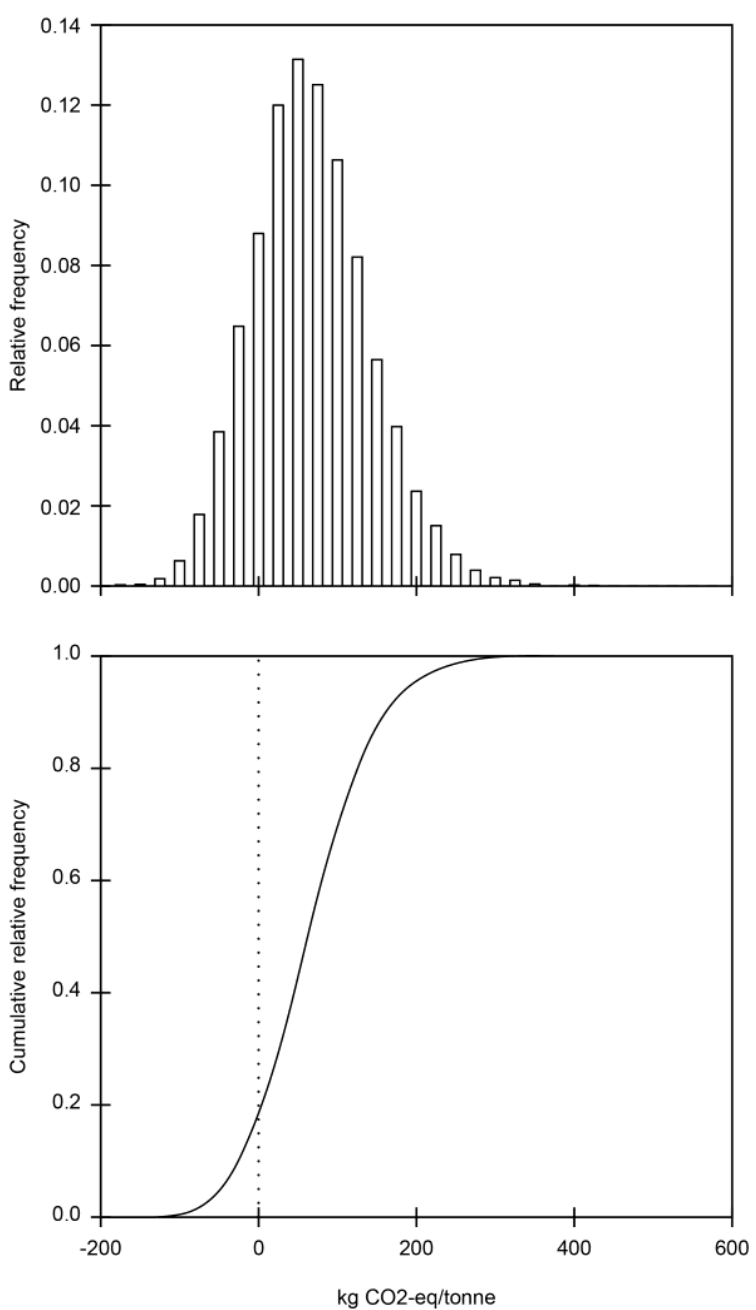

Figure 5: Relative frequency histograms and cumulative relative frequencies for the difference between global warming factors of the anaerobic digestion and the incineration scenarios. A positive difference implies that incineration is preferable to anaerobic digestion. 


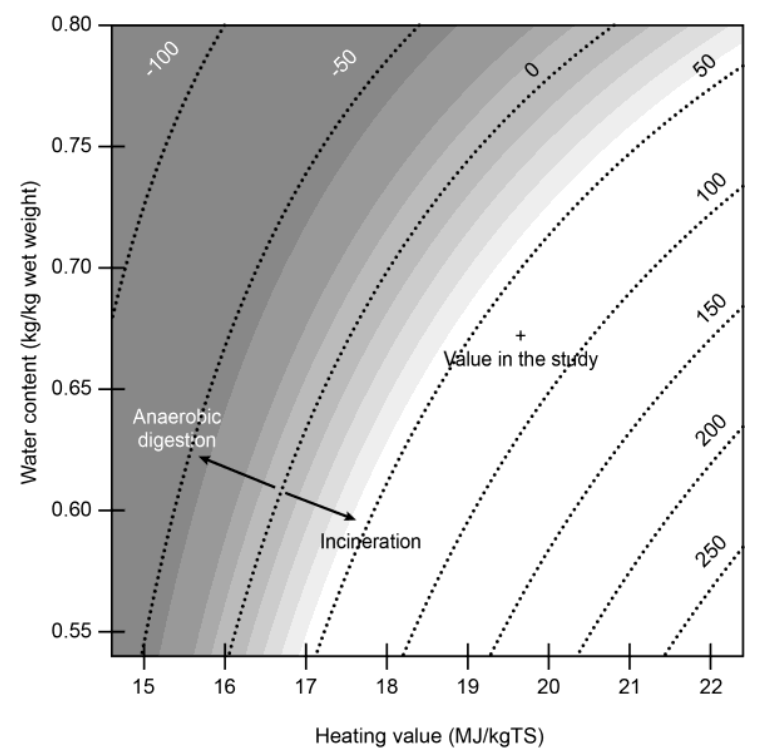

Figure 6: Contour lines of the difference between the global warming factors of the two scenarios (in $\mathrm{kg} \mathrm{CO}_{2}$-eq /

929 tonne) with two parameters variations. The bottom right area shows the conditions where incineration should be

930 preferred while in the top left anaerobic digestion should be favoured.

931

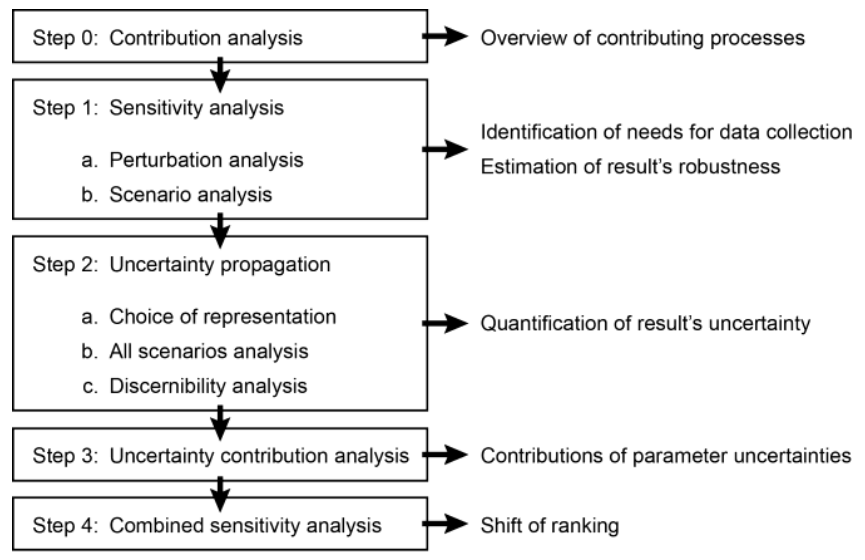

932

933 Figure 7: A sequential approach for qualitative uncertainty analysis. 